\title{
QUANTIDADE ABSORVIDA E CONCENTRAÇÕES DE MICRONUTRIENTES EM TOMATEIRO SOB CULTIVO PROTEGIDO
}

\author{
Domingos Sávio Rodrigues ${ }^{1 *}$; Adriana Luzia Pontes²; Keigo Minami³ Carlos Tadeu dos Santos \\ $\operatorname{Dias}^{4}$ \\ ${ }^{1}$ Pós-Graduando em Horticultura - UNESP/FCA, C.P. 237 - CEP: 18603-970 - Botucatu, SP. \\ ${ }_{3}^{2}$ Pós-Graduanda em Fitotecnia - USP/ESALQ. \\ ${ }^{3}$ Depto. de Produção Vegetal - USP/ESALQ, C.P. 09 - CEP: 13418-900 - Piracicaba, SP. \\ ${ }^{4}$ Depto. de Ciências Exatas - USP/ESALQ. \\ *Autor correspondente <drodrigues@fca.unesp.br>
}

RESUMO: A produção sob cultivo protegido é uma prática relativamente recente no Brasil e a área com tomate nesse ambiente vem crescendo a cada ano, e junto com esse crescimento, cresce também a falta de informações técnicas apropriadas para as nossa condições. Este trabalho avaliou a quantidade absorvida e os teores de micronutrientes pelo tomateiro em ambiente protegido. Foram utilizados diferentes fertilizantes, via solo, foliar e fertirrigação, foi utilizada a cultivar Lúcia, o experimento foi instalado em Piracicaba-SP, no período de dez/95 a março/96. O delineamento utilizado foi o aleatorizados em blocos, com três tratamentos e seis repetições. Em média, a planta apresentou na época do florescimento (35 dias após transplante) a seguinte concentração em mg kg ${ }^{-1}: 56,1$ de B; 107,8 de Cu, 440,4 de Fe; 313,8 de Mn e 194,9 de Zn. Para uma produção de $10.2 \mathrm{~kg} \mathrm{~m}^{-2}$ a planta extraiu em $\mathrm{g} \mathrm{m}^{-2}: 0,0274$ de B; 0,0826 de Cu; 0,1694 de Fe; 0,1702 de Mn e 0,1133 de $\mathrm{Zn}$.

Palavras-chave: Lycopersicon esculentum, fertirrigação, nutrição, hortaliça

\section{CONTENT AND CONCENTRATIONS OF ABSORBED MICRONUTRIENTS IN TOMATOES UNDER PROTECTED CULTIVATION}

\begin{abstract}
Production under protected cultivation is a relatively new practice in Brazil, and the area planted to tomatoes in such an environment is increasing year by year. Along with this growth comes a lack of proper technical information regarding our present stand. This work evaluates the grade and the quantity of micronutrients absolved by the tomato plant in a protected environment. Fertilizers were applied via soil, leaves and fertirrigating, using the cultivar Lucia. The experiment was carried out in Piracicaba, SP, Brazil, from December/95 to March/96. A completely random design was used with three treatments and six replications. At the flowering stage, plants presented the following micronutrient concentrations in $\mathrm{mg} \mathrm{kg}^{-1}$ : 56.1 of $\mathrm{B} ; 107.8$ of $\mathrm{Cu}, 440.4$ of $\mathrm{Fe} ; 313.8$ of $\mathrm{Mn}$ e 194.9 of $\mathrm{Zn}$. For a yield of $10.2 \mathrm{~kg} \mathrm{~m}^{-2}$, plants extracted the following quantities of nutrient in $\mathrm{g} \mathrm{m}^{-2}: 0.0274$ of $\mathrm{B} ; 0.0826$ of $\mathrm{Cu} ; 0.1694$ of Fe; 0.1702 of $\mathrm{Mn}$ e 0.1133 of $\mathrm{Zn}$. Key words: Lycopersicon esculentum, fertirrigation, nutrition, vegetable
\end{abstract}

\section{INTRODUÇÃO}

Considerando-se os aspectos sócio-econômicos, a cultura do tomateiro é hoje, dentre as hortaliças produzidas no Brasil, a mais importante. Comparandose as décadas de 70 e 80 , observa-se que no Brasil a produtividade aumentou em $49 \%$ e a área cultivada em $11 \%$, evidenciando a evolução da produção de tomate nos principais estados produtores. Na Região Sul, embora tenha aumentado a produtividade em $25 \%$, a área cultivada manteve-se estável, no Rio de Janeiro a situação foi similar. A Região Nordeste aumentou sua produção em $131 \%$ graças à expansão da área cultivada e ao aumento da produtividade nos períodos de 197180 e 1981-90. A produção brasileira de tomate é de aproximadamente 2,6 milhões de toneladas numa área aproximada de 60.400 ha, com uma produtividade média de 43,04 tha-1. Os estados que mais produzem são São Paulo, Pernambuco, Goiás e Bahia (Agrianual, 1996; Camargo Filho \& Mazzei, 1996)

Os solos cultivados com a cultura do tomateiro apresentam características completamente diferentes, com sérias implicações na recomendação do correto uso de fertilizantes e corretivos. No cultivo intensivo, é comum encontrar-se solos com teores elevados dos nutrientes essenciais para o desenvolvimento das plantas, porém completamente desbalanceados entre si. Já no cultivo nômade, é comum encontrarem solos onde os nutrientes minerais encontram-se em concentrações menores do que aquelas requeridas para o cultivo econômico das hortaliças (Takazaki \& Della Vecchia, 1993).

Para adubações, quando eram realizadas em áreas de terceiros, não se percebia o problema do desequilíbrio nutricional, porém, à medida que os 
agricultores deixaram de ser nômades e iniciaram o uso mais intensivo de suas propriedades, em função da adição maciça de nutrientes e da sensível depauperação da matéria orgânica do solo, esse fenômeno tornou-se mais freqüente (Takahashi, 1993).

Fernandes et al.(1975), em um experimento de marcha de absorção de nutrientes em condições de campo, em um solo Latossolo Roxo, concluíram que uma cultura de tomate, com 57.000 plantas/ha e uma produção de 41 toneladas, absorve as seguintes quantidades em $\mathrm{g} \mathrm{m}^{-2}$ : B-0,0086; Cu-0,0037; Fe-0,135; Mn-0,0393; Zn-0,0119.

Fayad (1998) cultivando tomate em ambiente protegido obteve a seguinte absorção em $\mathrm{g} \mathrm{m}^{-2}: 0,32 \mathrm{de}$ $\mathrm{Mn}, 0,21$ de $\mathrm{Fe}, 0,16$ de Cu e 0,07 de Zn.

Com experimento de marcha de absorção dos nutrientes pelo tomateiro industrial, Haag et al. (1981) observaram que o crescimento da cultura foi lento até os 30 dias, após há um crescimento acelerado, com o peso do material seco, dobrando a cada quinzena no período dos 45 aos $75 \mathrm{DAT}^{1}$, atingindo o máximo com 105 DAT. Os frutos cresceram em peso de material seco, cerca de 20 vezes no intervalo de 45 até 75 DAT duplicando o peso, no período de 75 até 90 dias e estabilizando-se aos 105 DAT. Na época da floração, as folhas apresentavam, em função do material seco em mg kg-1: B-72; Cu-15; Fe-434; Mn-375; Mo-0,18 e $\mathrm{Zn}-148$. A produção efetiva de $65 \mathrm{tha}^{-1}$ de frutos contém: 93g B; $45 \mathrm{~g} \mathrm{Cu} ; 547 \mathrm{~g} \mathrm{Fe} ; 163 \mathrm{~g} \mathrm{Mn;} \mathrm{485mg} \mathrm{Mo}$ e $321 \mathrm{~g} \mathrm{Zn}$.

Stripari (1999) cultivando o Híbrido Momotaro em ambiente protegido obteve a seguinte concentração em mg kg${ }^{-1}: \mathrm{Fe}-119,2$ a 137,0, Zn - 56,6 a 114,5, Cu 15,6 a 40,4, Mn - 106,1 a 340,9 e B - 58,4 a 75,3. Costa (1999) com o Momotaro em soluções nutritivas obteve em média a seguinte concentração em $\mathrm{mg} \mathrm{kg}^{-1}$ : B-67,8, Cu-15,8, Fe-141, Mn-117 e Zn-28,4.

A ordem de absorção de micronutrientes pela cultura do tomateiro é $\mathrm{Fe}, \mathrm{Zn}, \mathrm{B}, \mathrm{Mn}$ e $\mathrm{Cu}$. Embora não tenha apresentado valores para Mo, sabe-se que este é o absorvido em menor quantidade, para quase a totalidade das culturas Segundo Castellane (1982).

Até hoje, a pesquisa brasileira, na área de nutrição e adubação mineral de hortaliças, parece terse preocupado em gerar conhecimento e resultados mais para o cultivo nômade de hortaliça. Porém, no cultivo protegido, a forma de aplicação de nutrientes precisa ser diferenciada em relação ao campo, pois o produtor, utilizando-se de uma estrutura de boa qualidade, sementes de alto valor, bom sistema de irrigação, deverá utilizar critérios técnicos específicos para que a planta receba a quantidade ideal e que não ocorra desperdício de fertilizantes, pois além de ser oneroso, nesse sistema não ocorrem chuvas, podendo ocorrer danos irreparáveis ao solo, como a salinização por exemplo.
Freire et al. (1980) trabalharam com formas diferentes de aplicação de nutrientes e relatam o seguinte: a adubação foliar é um meio eficiente no suprimento de nutrientes para a planta. Em se tratando do fornecimento de macronutrientes, a adubação foliar deve ser encarada como, um complemento da adubação no solo e nunca como substitutiva, pois, pelas exigências nutricionais do tomateiro, verifica-se que seria necessário um número elevado de pulverizações, para suprir as necessidades da planta, o que seria antieconômico. Para os micronutrientes, exigidos em pequenas quantidades, a adubação foliar poderá suprir todas as exigências da cultura.

A adubação foliar não pode substituir totalmente o fornecimento de adubos ao solo, através da absorção pelas raízes Camargo \& Silva (1990). Entretanto, a expansão do uso da adubação foliar a um número cada vez maior de culturas, vem demonstrando que há culturas que podem ser mantidas, em relação a determinados nutrientes, quase que exclusivamente por via foliar. Afirmam também, que a adubação foliar tem, ainda, a vantagem de ser de baixo custo, e de poder ser aplicada em mistura com vários defensivos agrícolas, nas pulverizações fitossanitárias.

A adubação foliar é uma técnica de utilização muito restrita (Minami (1986). Há algumas condições para o seu uso, senão os resultados podem ser desastrosos. A adubação de plantio deve ser bem feita e o estado de sanidade da cultura deve ser bom, pois ela não corrige um estado de carência, quando muito temporariamente. A adubação foliar deve ser usada complementarmente à adubação convencional e só deve ser usada em determinadas fases de desenvolvimento da cultura. A concentração dos nutrientes e o intervalo mínimo e máximo entre uma e outra aplicação devem ser muito bem observados.

Já a fertirrigação em nosso país, somente nestes últimos anos é que tem se firmado como técnica, mesmo assim, seu uso, quando comparado ao seu potencial, pode ser considerado incipiente. Proprietários de sistemas de irrigação localizada e de pivô-central são os que fazem uso mais freqüente da técnica, notadamente para a aplicação de adubos nitrogenados (Hernandez, 1994).

A aplicação de fertilizantes através da água de irrigação é uma prática que pode ser associada aos sistemas de irrigação localizada e tipos de aspersão. Essa prática, denominada fertirrigação, constitui-se numa técnica de aplicação simultânea de fertilizantes e água ao solo, através de um sistema de irrigação. É uma prática agrícola essencial para o manejo de culturas irrigadas, quando se utiliza sistema de irrigação localizada, sendo uma das maneiras mais eficientes e econômicas de aplicar fertilizantes nas plantas, principalmente nas regiões de climas áridos e semi-

1DAT - dias após transplante 
áridos, pois aplicando-se os fertilizantes em menor quantidade por vez, mas com maior freqüência, é possível manter-se um nível uniforme de nutrientes no solo, durante o ciclo vegetativo da cultura, o que aumentará a eficiência do uso de nutrientes pelas plantas e, consequentemente, a sua produtividade (Bernardo, 1986, Villas Boas et al., 1994).

Os problemas de fertilidade do solo no cultivo protegido poderão ser ainda maiores do que os do cultivo intensivo a céu aberto, pois pela proteção proporcionada contra as chuvas, evita lixiviação de nutrientes e, aumenta a sua concentração na camada de solo explorada pelas raízes. Necessita-se ainda, de conhecimentos e informações geradas nas condições de solo, clima, cultivo e cultivares disponíveis no Brasil (Takazaki \& Della Vecchia, 1993).

A produção sob cultivo protegido é uma prática relativamente recente no nosso país e faltam ainda informações técnicas na recomendação de nutrientes; formas de aplicação, etc. Este trabalho teve como objetivo, estudar a forma de aplicação de fertilizantes via solo, via foliar e via água de irrigação, denominada fertirrigação influenciando o desenvolvimento a produtividade da planta, teores e quantidades absorvidas de micronutrientes pelo tomateiro sob cultivo protegido.

\section{MATERIAL E MÉTODOS}

O experimento foi realizado na área experimental do Departamento de Produção Vegetal da Escola Superior de Agricultura "Luiz de Queiroz" (ESALQ), da Universidade de São Paulo (USP) em Piracicaba-SP, localidade que tem as seguintes coordenadas geográficas: longitude: $47^{\circ} 38^{\prime} 00^{\prime \prime} \mathrm{W}$; latitude: $22^{\circ} 42^{\prime} 30^{\prime \prime}$ $\mathrm{S}$ e uma altitude de $580 \mathrm{~m}$.

A caracterização química do solo na área do experimento é apresentada na Tabela 1, com macronutrientes extraídos por resina e os micronutrientes por DTPA.

A estufa foi do tipo túnel, coberta com lençol de polietileno com espessura de $0,150 \mathrm{~mm}$, lateralmente envolta com o mesmo material da cobertura até a altura de $100 \mathrm{~cm}$ do nível do solo (saia), e com tela de $50 \%$ de sombreamento. A estufa possui $25 \mathrm{~m}$ de comprimento e $7 \mathrm{~m}$ de largura, com 4,0 m de altura na parte central, totalizando uma área de $175 \mathrm{~m}^{2}$.

Como adubação de plantio foi utilizada a fórmula 4-14-8, na dose de $400 \mathrm{~g} \mathrm{~m}^{-2}$, aplicada e incorporada 15 dias antes do transplante na área total da estufa.
$\mathrm{Na}$ adubação convencional (fertilizantes colocados no pé da planta) foram usados na adubação de cobertura $10 \mathrm{~g}$ planta $^{-1}$ de $\mathrm{KCl}$ e de Uréia, em intervalos de 15 dias.

$\mathrm{Na}$ fertirrigação foi utilizado o fertilizante com a seguinte formulação em g kg${ }^{-1}: \mathrm{N}-100, \mathrm{P}_{2} \mathrm{O}_{5}-30, \mathrm{~K}_{2} \mathrm{O}-$ 70 , aplicando-se $15 \mathrm{~L} \mathrm{ha}^{-1}$ até os 30 dias após transplante e, $40 \mathrm{~L} \mathrm{ha} \mathrm{h}^{-1}$ duas vezes por semana, após os 31 dias do transplante.

$\mathrm{Na}$ adubação foliar foram utilizados fertilizantes com as seguinte formulações em g kg-1: $\mathrm{N}-140,0 ; \mathrm{P}_{2} \mathrm{O}_{5}-$ 40,0; K O-60,0; S-8,0; Mg-15,0 e em mg kg-1 Zn-20,0 Mn15,0 B-1,0; Mo-0,5 e Ca-80,0 (g kg $)$, B-5,0 $\left(\mathrm{mg} \mathrm{kg}^{-1}\right)$ e $\mathrm{Cl}-15,0\left(\mathrm{mg} \mathrm{kg}^{-1}\right)$, na dosagem de $10 \mathrm{~L} \mathrm{ha}{ }^{-1}$, na proporção de $0,3 \%$, aplicados duas vezes por semana.

As coletas foram feitas para análise da marcha de absorção, com intervalo de 14 dias, foram feitas no ato do transplante, aos $21,35,49,63,77,91,105$ DAT. As amostras, planta inteira sem a raiz, foram encaminhadas ao Laboratório do Departamento de Solos e Nutrição de Plantas, para as análises químicas nas plantas, utilizandose o método descrito por Sarruge \& Haag (1974).

A colheita teve início aos 60 dias após o transplante, os frutos foram colhidos quando se apresentavam "de vez". Foram feitas no total quatro colheitas, onde foram medidos: o peso, a classificação pelo diâmetro e o número de frutos por plantas.

Foram feitas apenas quatro colheitas, pelo fato da grande incidência de pragas: traças (Scrobipalpula absoluta Meirick), mosca minadora (Lyriomiza spp.), tripes (Frankliniella schulzei Trybom.), ácaro do bronzeado (Aculops lycopersici Massee.), broca pequena do fruto (Neoleucinodes elegantis Guenee.) e doenças: talo oco (Erwinia carotovora Jones), requeima (Phytophthora infestans Mont), oídio (Oidium lycopersici Cooke \& Mass ), podridão de phoma (Phoma destructiva Plowr). Doenças e pragas ocorreram semelhantes em todo o experimento.

$O$ delineamento experimental adotado em blocos casualizados, com três tratamentos e seis repetições, sendo o espaçamento de $0,80 \times 0,20 \mathrm{~m}$. Cada parcela ocupou uma área de 4,0 x 1,0 m, correspondendo a 20 plantas, como no decorrer do experimento, foram coletadas 8 plantas para análise de marcha de absorção de nutrientes, o espaçamento final ficou de $0,80 \mathrm{x}$ $0,40 \mathrm{~m}$, totalizando 12 plantas/parcela, correspondendo a 3,1 plantas $\mathrm{m}^{-2}$.

Os dados foram submetidos à análise de variância, empregando-se o teste $\mathrm{F}$ a $5 \%$. A comparação entre médias foi feita através do teste de Tukey a $5 \%$.

Tabela 1 - Características químicas do solo da área experimental.

\begin{tabular}{|c|c|c|c|c|c|c|c|c|c|c|c|c|c|}
\hline $\begin{array}{c}\mathrm{pH} \\
\mathrm{CaCl}_{2}\end{array}$ & M.O. & P.res & $\mathrm{K}$ & $\mathrm{Ca}$ & $\mathrm{Mg}$ & $\mathrm{H}+\mathrm{Al}$ & SB & CTC & V & $\mathrm{Cu}$ & $\mathrm{Fe}$ & $\mathrm{Mn}$ & $\mathrm{Zn}$ \\
\hline & $\mathrm{g} \mathrm{kg}^{-1}$ & $\mathrm{mg} \mathrm{kg}^{-1}$ & ------- & - & mm & ol d m $\mathrm{m}^{-3}$ & -------- & ------ & $\%$ & --------- & ----- m & $\mathrm{g} \mathrm{kg}^{-1}$ & ------- \\
\hline $5,7 \mathrm{a}$ & $2,23 \mathrm{~m}$ & $52,9 a$ & $3,6 \mathrm{a}$ & $41,6 a$ & $12,9 a$ & $36,1 \mathrm{~m}$ & $58 a$ & $94 a$ & $62 \mathrm{~m}$ & $7,25 \mathrm{~m}$ & $22,7 \mathrm{a}$ & $51,6 \mathrm{~m}$ & $5,5 a$ \\
\hline
\end{tabular}

b-baixo; m-médio; a-alto; classificação segundo Raij et al. (1996). 
Os tratamentos foram modos de aplicação dos nutrientes: A - Adubação de cobertura convencional (no solo); B - Adubação foliar e C - Fertirrigação.

Foram avaliados: altura da planta; Acúmulo de material seco em várias fases de crescimento; teores e absorção de micronutrientes em função da idade da planta e do seu peso seco; Número, peso médio e Produção total de frutos por planta.

\section{RESULTADOS E DISCUSSÃO}

Não ocorreu diferença na altura das plantas entre os tratamentos em nenhum período do experimento (Tabela 3). A planta teve um rápido crescimento inicial. A altura dobrou a cada duas semanas, até os 35 dias e, a partir daí diminuiu seu ritmo de crescimento, atingindo $248,8 \mathrm{~cm}$ aos 105 DAT. Resultado próximo dos 228,0 e $246,0 \mathrm{~cm}$ encontrados por Dechen (1980) que cultivou as variedades Kada e Samano. Resultados diferentes, porém, foram observados por Gargantini \& Blanco (1963), que cultivaram a variedade Santa Cruz 1639 em vasos, onde as plantas tiveram um lento crescimento inicial até os trinta dias, daí passando a ter um crescimento mais acelerado até os 100 DAT onde atingiram $134 \mathrm{~cm}$.

Não houve diferenças no acúmulo de material seco em função dos tratamentos, conforme a Tabela 4. A planta teve um rápido crescimento no período inicial, dos 21 aos 35 dias após transplante, o seu peso de material seco praticamente quadruplicou e, dos 35 aos 63 DAT, o peso de material seco foi dobrando, chegando ao máximo aos 91 DAT, quando produziu um total de $7,281 \mathrm{~g} \mathrm{~m}^{-2}$, sendo $5,575 \mathrm{~g}$, pela parte vegetativa e 1,706 pelos frutos e flores, correspondendo a 76,6 e $23,4 \%$ respectivamente, resultados próximos dos $8,415 \mathrm{~g} \mathrm{~m}^{-2}$, encontrados por Haag et al. (1981), porém bem abaixo dos 18,770 e $20,413 \mathrm{~g} \mathrm{~m}^{-2}$, encontrados por Ward (1967) e Maher (1976) Figura 1.

Nas concentrações de Boro (em $\mathrm{mg} \mathrm{kg}^{-1}$ ), na planta, houve diferença aos 49, 63, 77 e 91 DAT, onde a adubação foliar, obteve as maiores médias, diferindo estatisticamente das adubações convencional e fertirrigação. Talvez esse resultado tenha ocorrido pelo fato da parcela com adubação foliar receber o Boro diretamente nas folhas. Além disso o experimento foi realizado em ambiente protegido onde não ocorreu a lavagem de nutrientes pela chuva. Nos frutos, não houve diferença significativa em nenhuma fase de crescimento. O Boro teve sua concentração máxima aos 49 dias, permanecendo no mesmo nível até os 77 dias, alcançando o teor de $56,07 \mathrm{mg} \mathrm{kg}^{-1}$. Os teores de $\mathrm{B}$ ficaram na faixa considerada adequada (30-100 $\mathrm{mg} \mathrm{kg}^{-1}$ ) por Raij et al. (1996) em todas as fases, com exceção dos 21 DAT. Porém ficaram abaixo dos (50-70 $\mathrm{mg} \mathrm{kg}^{-1}$ ) limites adequados considerados por Malavolta et al. (1997), Figura 3.
A quantidade absorvida de $B$ foi diferente entre os tratamentos, na planta, aos 63, 77 e 91 DAT, sendo a adubação foliar superior às demais adubações. Em relação aos frutos não houve diferença significativa. A quantidade de Boro absorvida praticamente dobrou a cada duas semanas, até chegar aos 63 dias, diminuindo a partir daí, seu ritmo de crescimento, Figura 2. Aos 91 DAT foi absorvido em maior quantidade, sendo que para uma população de 3,12 plantas por $\mathrm{m}^{2}$, extraiu um total de $0,0274 \mathrm{~g}$. Resultados esses bem acima dos 0,0086 e $0,0093 \mathrm{~g}$, encontrados por Fernandes et al. (1975) e Haag et al. (1981), respectivamente, com experimentos com tomate industrial em campo. Como explicado anteriormente, esse resultado considerado alto em relação a outros autores, pode ser pelo fato de não ocorrer lavagens de nutrientes pela chuva e por ter obtido produção superior.

Houve diferença entre os tratamentos em relação ao teor de cobre na planta, apenas aos 35 DAT. A adubação foliar obteve as maiores médias, diferindo estatisticamente das demais adubações. Nos frutos não ocorreu diferença significativa entre os tratamentos, em nenhuma das fases de crescimento. A planta apresentou um alto teor de $\mathrm{Cu}$, oscilando entre 88,3 a $152,4 \mathrm{mg} \mathrm{kg}^{-1}$, Figura 3. Os teores de Cu ficaram acima da faixa (5-15 $\left.\mathrm{mg} \mathrm{kg}^{-1}\right)$ considerada adequada por Raij et al.

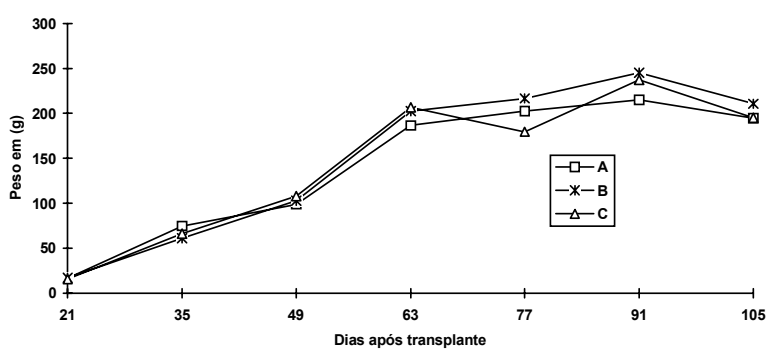

Figura 1 - Curvas de crescimento do acúmulo de material seco do tomateiro, em várias fases de crescimento.

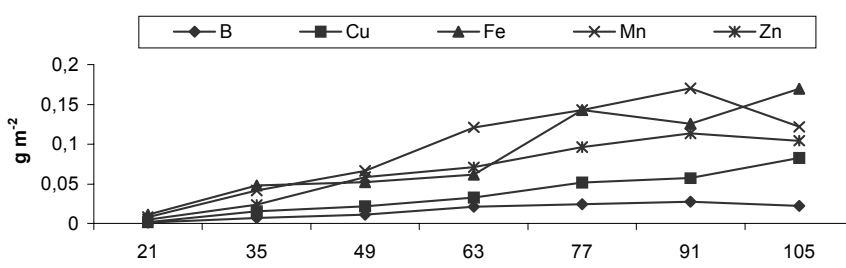

Figura 2 - Marcha de absorção de micronutrientes pelo tomateiro, aos $21,35,49,63,77,91$ e 105 dias após transplante.

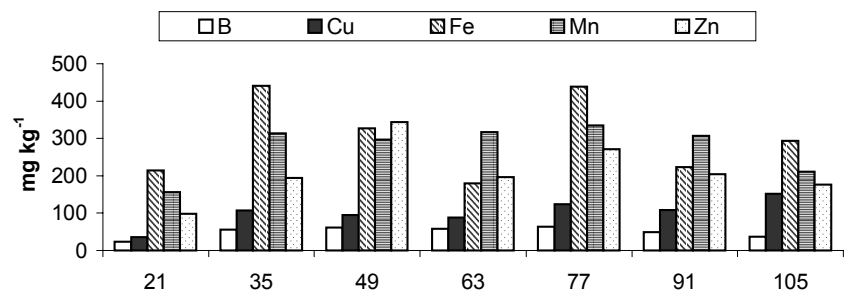

Figura 3 - Concentração $\left(\mathrm{mg} \mathrm{kg}^{-1}\right)$ dos micronutrientes no tomateiro, aos $21,35,49,63,77,91$ e 105 dias após transplante. 
(1996). Quanto à quantidade absorvida de $\mathrm{Cu}$, na planta e nos frutos, não houve diferença significativa entre os tratamentos. O Cu nas primeiras duas semanas teve sua absorção aumentada em oito vezes, Figura 2. Aos 105 DAT, a planta a absorveu o equivalente a $0,0826 \mathrm{~g} \mathrm{~m}^{-2}$. Desse total, $0,0821 \mathrm{~g}$ foi absorvido pela planta e $0,00053 \mathrm{~g}$ exportados. No entanto, é bom observar que, apesar do alto teor de cobre na planta, muito pouco foi translocado para os frutos. Os resultados assemelham-se aos encontrados por Haag et al. (1981).

Nos teores e nas quantidades absorvidas de $\mathrm{Fe}$ pela planta houve diferença na planta apenas aos 77 DAT, onde as adubações foliares e convencional diferiram da fertirrigação, tendo a fertirrigação causando a menor média. Porém em relação aos teores nos frutos não ocorreu diferença significativa. Enquanto que para as quantidades absorvidas pelos frutos houve diferença apenas aos 49 DAT. Onde a adubação foliar diferiu da adubação convencional. O maior teor de Fe na planta foi aos 35 DAT, atingindo $440,4 \mathrm{mg} \mathrm{kg}^{-1}$, período que coincidiu com o início do florescimento. Entre 49 e 77 DAT ocorreu uma oscilação decrescendo daí até o final do ciclo da cultura, Figura 2. Os teores de Fe ficaram acima da faixa (100-300 mg kg-1) considerada adequada por Raij et al. (1996). O alto teor desse nutriente na planta, durante todo o seu ciclo é normal, segundo Lyon et al. (1943) que obteve resultados semelhantes. Segundo Malavolta (1980) a deficiência do ferro ocorre geralmente devido a uma diminuição na disponibilidade ou na absorção, não sendo causada por falta propriamente dita. Pode ser esse o motivo da oscilação dos teores desse nutriente na planta. $\mathrm{Na}$ absorção do Fe houve inicialmente uma evolução muito rápida, aumentando cinco vezes dos 21 aos 35 DAT oscilando daí, até os 105 DAT, quando ocorreu sua maior absorção, Figura 2. Totalizou-se $0,169 \mathrm{~g} \mathrm{~m}^{-2}$, nos quais $0,108 \mathrm{~g}$ permaneceram na parte vegetativa e $0,061 \mathrm{~g}$ foram exportados pelas flores e frutos, correspondendo a 64,2 e $35,8 \%$ respectivamente, resultados acima dos $0,135 \mathrm{~g}$, encontrados por Fernandes et al. (1975).

Em relação à quantidade absorvida e os teores de $\mathrm{Mn}$, observou-se diferença entre os tratamentos em várias fases de crescimento. Quanto aos teores na planta, a adubação foliar causou as maiores médias, diferindo estatisticamente da fertirrigação aos $21,63,77$, 91 e 105 DAT e da adubação convencional aos 35 e 105 DAT. Já nos frutos houve diferenças aos 63 dias onde a adubação foliar diferiu das demais e aos 105 DAT a adubação convencional causou a maior média. Os maiores teores de $\mathrm{Mn}$ foram observados aos 77 DAT chegando a $335,3 \mathrm{mg} \mathrm{kg}^{-1}$. Os teores de $\mathrm{Mn}$ ficaram acima da faixa $\left(50-250 \mathrm{mg} \mathrm{kg}^{-1}\right)$ considerada adequada por Raij et al. (1996).

Houve diferenças significativas entre os tratamentos, para quantidade absorvida de Mn pela planta, aos 21, 63, 77 e 105 DAT. A adubação foliar apresentou maior quantidade absorvida e diferiu da fertirrigação aos 21, 63, 77 e 105 DAT e a adubação convencional diferiu da fertirrigação aos 21 e 77 DAT. Já nos frutos houve diferenças aos 49, 63, 77 e 105 DAT. A adubação foliar causou as maiores médias e diferiu da fertirrigação aos 49, 77 DAT. Aos 63 DAT diferiu da adubação convencional e aos 105 DAT a adubação convencional causou a maior média. Essa diferença deve ser pelo fato da adubação foliar conter Manganês na sua formulação.

$\mathrm{Na}$ época de maior absorção desse nutriente pelo tomateiro, aos 91 dias, porém, os tratamentos não diferiram entre si.

A exemplo do $\mathrm{Fe}$, a absorção do $\mathrm{Mn}$ foi inicialmente muito rápida. Dos 21 aos 35 DAT aumentou em cinco vezes sua quantidade absorvida; dos 35 até os 91 DAT ocorreu uma diminuição no ritmo da absorção, Figura 2. Atingiu o ponto máximo aos $91 \mathrm{DAT}$, onde, para uma população de 3,12 plantas $\mathrm{m}^{-2}$, foi absorvido um total de $0,1702 \mathrm{~g}$, sendo $0,132 \mathrm{~g}$ absorvidos pela parte vegetativa e $0,0378 \mathrm{~g}$ exportados pelos frutos, correspondendo a 77,7 e 22,3\%, respectivamente.

Para os teores e quantidades absorvidas de $\mathrm{Zn}$ pela planta houve diferença entre os tratamentos. A adubação foliar diferiu estatisticamente das outras duas adubações em várias fases de crescimento. A adubação foliar causou as maiores médias de teores de $\mathrm{Zn}$ na planta aos 21, 35, 49, 63, 91 e 105 Dias após transplante e aos 77 DAT diferiu apenas da fertirrigação. Nos frutos ocorreu diferença aos dias 91 e 105 DAT, sendo que aos 91 dias a fertirrigação causou menor média diferindo das demais e aos 105 DAT a adubação convencional causou maior média diferindo das demais.

Com a adubação foliar a planta chegou aos 49 DAT com teor de $177,83 \mathrm{mg} \mathrm{kg}^{-1}$, enquanto no mesmo período, a adubação convencional causou $90,83 \mathrm{mg} \mathrm{kg}^{-1}$ e a fertirrigação $99,83 \mathrm{mg} \mathrm{kg}^{-1}$. Os teores de $\mathrm{Zn}$ ficaram acima da faixa (30-100 mg kg-1) considerada adequada nas folhas de tomateiro por Raij et al. (1996).

Quanto à quantidade absorvida de $\mathrm{Zn}$ pela planta houve diferença entre os tratamentos em várias fases de crescimento, tanto na planta como nos frutos. A adubação foliar ocasionou as maiores médias, diferindo estatisticamente das adubações convencional e fertirrigação aos 21, 35, 49, 63, 91 e 105 DAT, e somente da fertirrigação aos 77 DAT. Já nos frutos, a adubação foliar ocasionou as maiores médias, diferindo estatisticamente da convencional e fertirrigação aos 63 e 77 DAT, e somente da fertirrigação aos 91 e 105 DAT.

O período de maior absorção desse nutriente foi aos 91 dias, quando o tratamento com a adubação foliar atingiu $0,1798 \mathrm{~g} \mathrm{~m}^{-2}$. Já com as adubações convencional e fertirrigação, na mesma época, as quantidades absorvidas foram de 0,0735 e $0,086 \mathrm{~g}$ respectivamente, Figura 2.

Em várias datas a adubação foliar causou as maiores médias, em teores e quantidades absorvidas de nutrientes pela planta. Isso pode ter ocorrido pelo fato de na adubação foliar, os nutrientes foram pulverizados diretamente na parte aérea da planta. 
Número de frutos médios, miúdos e total por planta, Peso por fruto e por planta nos diferentes tratamentos

Observa-se na Tabela 5 que não houve diferença entre os tratamentos, para peso por frutos, por plantas, número de frutos médios, miúdos e total de frutos por planta.

De acordo com Ho \& Hewitt (1986), a produção da cultura do tomate é determinada pelo número de frutos e pelo peso deles. Observa-se, através das médias dos pesos por frutos e peso por plantas, (Tabela 5), que com uma população de 3,1 plantas $\mathrm{m}^{-2}$, tem-se uma produção, em torno de $10,2 \mathrm{~kg} \mathrm{~m}^{-2}$, resultado esse semelhante a $10,3 \mathrm{~kg} \mathrm{~m}^{-2}$, encontrado em Jaboticabal por Martins (1992).

Essa produção, provavelmente seria mais alta, não fossem as altas temperaturas durante todo 0 período de desenvolvimento vegetativo e reprodutivo, (Tabela 2), e o pequeno período de colheita (quatro colheitas).

Ainda segundo Ho \& Hewitt, (1986) no estágio de florescimento, o tomateiro tolera poucas horas com temperatura acima de $40^{\circ} \mathrm{C}$, o que, pode afetar negativamente a viabilidade dos óvulos, a deiscência das anteras e a transferência do pólen. Temperaturas noturnas acima de $26^{\circ} \mathrm{C}$ ou diurnas acima de $40^{\circ} \mathrm{C}$ e temperaturas abaixo de $10^{\circ} \mathrm{C}$ causam muitos danos à cultura do tomateiro.

A adubação foliar que causou as maiores médias nas quantidades absorvidas e nos teores de nutrientes na planta, não teve esses resultados influenciando na produção e no desenvolvimento do tomateiro.

A planta apresentou um rápido crescimento inicial, quadruplicando o seu peso seco e a altura dos 21 aos 35 dias, diminuindo depois o ritmo de crescimento. Aos $91 \mathrm{DAT}$, a produção de material seco atingiu o ponto máximo, com $7,28 \mathrm{~g} \mathrm{~m}^{-2}$, e aos 105 dias após transplante atinge $248,8 \mathrm{~cm}$ de altura, constatandose o máximo crescimento. Para um período de quatro colheitas, a planta na média geral apresentou 16,5 fru pls $^{-1}$ com peso médio de $193,5 \mathrm{~g}$ e a produção total foi de $10,2 \mathrm{~kg} \mathrm{~m}^{-2}$.

Não houve diferença no desenvolvimento e produção de tomate em relação aos métodos de aplicação de fertilizantes, utilizados no experimento. Talvez pelo fato do experimento ter sido realizado num solo de boa fertilidade (Tabela 1) capaz de fornecer boa quantidade de nutrientes às plantas. As quantidades de nutrientes utilizadas nos tratamentos, praticamente não influenciaram no desenvolvimento e na produção do tomateiro.

Os maiores teores de micronutrientes na planta e nos frutos ocorreram entre os 35 e 49 dias após transplante. Na época do florescimento, aos 35 DAT, em função do peso de material seco, as plantas apresentaram a seguinte concentração de micronutrientes em mg kg${ }^{-1}: 56,1$ de $\mathrm{B} ; 107,8$ de $\mathrm{Cu}$; 440,4 de Fe; 313,8 de $\mathrm{Mn} ; 194,9$ de Zn. Aos 63 DAT em função do peso de material seco, as plantas apresentam a seguinte concentração de micronutrientes em mg kg-1: 58,9 de B; 88,3 de Cu; 179,4 de Fe; 316,3 de $\mathrm{Mn}$ e 195,8 de Zn. Para uma produção de $10.2 \mathrm{~kg}$ $\mathrm{m}^{-2}$ a planta absorveu em g: 0,0274 de $\mathrm{B} ; 0,0826 \mathrm{de}$ $\mathrm{Cu} ; 0,169$ de Fe; 0,170 de $\mathrm{Mn}$ e 0,113 g de $\mathrm{Zn}$. As datas 35 e 63 DAT foram citadas, pois aos 35 DAT, início do florescimento, a planta apresentou os maiores teores de nutrientes e aos 63 DAT, a planta apresentava-se no ápice de sua atividade metabólica, com $2 / 3$ do seu ciclo completo.

Tabela 2 - Valores médios de temperatura e umidade relativa, dentro e fora da estufa. USP/ESALQ, Piracicaba-SP, 1995/1996.

\begin{tabular}{|c|c|c|c|c|c|c|c|c|}
\hline \multirow[b]{2}{*}{ Mês } & \multicolumn{4}{|c|}{ Dado coletado dentro da estufa } & \multicolumn{4}{|c|}{ Dado coletado fora da estufa } \\
\hline & $\mathrm{T}^{\circ} \max$. & $\mathrm{T}^{\circ} \min$. & $\mathrm{T}^{\circ}$ media & U.R. \%. & $\mathrm{T}^{\circ} \max$. & $\mathrm{T}^{\circ} \mathrm{min}$. & $\mathrm{T}^{\circ}$ Média. & U.R. \% \\
\hline Dezembro/95 & 41 & 19 & 30 & 55 & 30 & 18 & 24 & 77 \\
\hline Janeiro/96 & 41 & 20 & 30 & 56 & 31 & 20 & 25 & 80 \\
\hline Fevereiro/96 & 44 & 19 & 31 & 69 & 31 & 20 & 25 & 84 \\
\hline Março/96 & 42 & 18 & 30 & 66 & 30 & 19 & 24 & 84 \\
\hline
\end{tabular}

Tabela 3 - Valores médios da altura das plantas de tomateiro aos 14, 21, 35, 49, 63, 77, 91 e 105 Dias após transplante.

\begin{tabular}{|c|c|c|c|c|c|c|c|c|}
\hline Tratame nto & 14 & 21 & 35 & 49 & 63 & 77 & 91 & 105 \\
\hline \multicolumn{9}{|c|}{ - } \\
\hline Solo & 36,4 a & 68,5 a & 135,4 a & 161,9 a & 196,7 a & 217,0 a & 230,8 a & 235,0 a \\
\hline Foliar & $37,0 \mathrm{a}$ & 69,9 a & 132,3 a & $162,4 \mathrm{a}$ & $198,2 \mathrm{a}$ & $220,2 \mathrm{a}$ & $242,2 \mathrm{a}$ & 254,1 a \\
\hline Fertirri. & $36,3 \mathrm{a}$ & $66,5 \mathrm{a}$ & $132,2 \mathrm{a}$ & $161,8 \mathrm{a}$ & 194,8 a & $215,7 a$ & $228,5 \mathrm{a}$ & 257,3 a \\
\hline Média & 36,6 & 68,3 & 133,4 & 162,0 & 196,5 & 217,6 & 233,8 & 248,8 \\
\hline D.M.S. & 4,5 & 4,9 & 7,6 & 5,8 & 12,2 & 13,2 & 13,9 & 23,5 \\
\hline C.V.\% & 8,1 & 4,3 & 3,7 & 2,4 & 4,1 & 4,8 & 3,9 & 6,3 \\
\hline
\end{tabular}


Tabela 4 - Acúmulo de material seco $(\mathrm{g})$ na planta e nos frutos de tomateiro em várias fases de crescimento aos dias 14 , 21, 35, 49, 63, 77, 91 e 105 dias após transplante.

\begin{tabular}{lccccccccccccc}
\hline Trat. & 21 & \multicolumn{2}{c}{35} & \multicolumn{2}{c}{49} & \multicolumn{2}{c}{63} & \multicolumn{2}{c}{77} & \multicolumn{2}{c}{91} & 105 \\
\hline & planta & Planta & Fruto & Planta & Fruto & Planta & fruto & planta & Fruto & planta & fruto & planta & Fruto \\
Solo & 16,6 a & 59,7 a & 15,2 a & 81,8 a & 17,5 a & 127,9 a & 59,2 a & 152,8 a & 50,0 a & 172,5 a & 43,0 a & 179,4 a & 16,8 a \\
Foliar & 17,0 a & 49,0 a & 12,8 a & 76,15 a & 27,0 a & 129,2 a & 74,0 a & 145,5 a & 70,0 a & 179,0 a & 66,6 a & 198,1 a & 17,1 a \\
Fertirri & 15,4 a & 49,0 a & 17,8 a & 87,26 a & 21,2 a & 132,2 a & 91,3 a & 134,2 a & 45,8 a & 183,7 a & 54,2 a & 179,7 a & 13,7 a \\
\hline Média & 16,3 & 52,6 & 15,2 & 81,73 & 21,9 & 129,8 & 74,8 & 144,1 & 55,3 & 178,4 & 54,6 & 185,7 & 15,2 \\
\hline D.M.S. & 5,27 & 19,2 & 14,8 & 38,4 & 11,15 & 45,95 & 49,05 & 34,47 & 38,26 & 31,23 & 40,42 & 51,13 & 5,13 \\
\hline C.V. \% & 21,4 & 24,3 & 27,4 & 18,3 & 17,5 & 11,9 & 21,4 & 8,0 & 21,3 & 11,6 & 24,6 & 18,3 & 30,9 \\
\hline
\end{tabular}

Tabela 5 - Massa média dos frutos, massa média por planta, número de frutos médios, miúdos e total de frutos por planta, nos diferentes tratamentos.

\begin{tabular}{|c|c|c|c|c|c|}
\hline \multirow[t]{2}{*}{ Tratamento } & \multicolumn{2}{|c|}{ 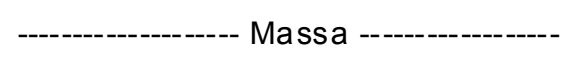 } & \multicolumn{2}{|c|}{$N^{\circ}$ fruto } & \multirow{2}{*}{$\frac{\mathrm{N}^{\circ} \text { Total }}{\text { fru }^{-1}}$} \\
\hline & $g$ fru ${ }^{1}$ & $\mathrm{~g} \mathrm{pl}^{-1}$ & médio & miúdo & \\
\hline Solo & $184,66 \mathrm{a}$ & 3050,50 a & $4,00 a$ & $11,83 \mathrm{a}$ & $16,16 \mathrm{a}$ \\
\hline Foliar & $202,00 \mathrm{a}$ & $3310,50 a$ & $6,50 a$ & $8,83 a$ & $16,00 \mathrm{a}$ \\
\hline Fertirrigação & $193,83 a$ & $3470,83 a$ & $5,83 a$ & 11,16 a & $17,50 \mathrm{a}$ \\
\hline Média & 193,50 & 3277,27 & 5,5 & 10,7 & 16,5 \\
\hline D.M.S. & 43,5 & 572,85 & 2,63 & 3,24 & 2,63 \\
\hline C.V.\% & 15,0 & 11,6 & 32,2 & 20,4 & 10,6 \\
\hline
\end{tabular}

\section{REFERÊNCIAS BIBLIOGRÁFICAS}

AGRIANUAL 1997: Anuário Estatístico da Agricultura Brasileira. São Paulo: FNP Consultoria \& Comércio, 1996. 435p.

BERNARDO, S. Manual de irrigação. 4.ed. Viçosa: Imprensa Universitária, 1986. 488p.

CAMARGO FILHO, W.P.; MAZZEI, A.R. Necessidade de reconversão da produção de tomate em São Paulo: ações na cadeia produtiva. Informações Econômicas, v.26, p.105-116, 1996.

CAMARGO, P.N.; SILVA, O. Manual de adubação foliar. São Paulo: Herba, 1990. 256p.

CASTELLANE, P.D. Nutrição mineral da cultura do tomateiro (Lycopersicon esculentum, Mill): I. Efeitos dos nutrientes na qualidade dos frutos. In: MULLER, J.J.V.; CASALI, V.W.D. (Ed.) Seminários de olericultura. Viçosa, 1982. v.3, p.113-157.

COSTA, P.C. Relações N:K:Ca na qualidade de frutos de tomateiro ((Lycopersicum esculentum, Mill.) Híbrido Momotaro, em cultivo hidrpônico. Botucatu, 1999. 73p. Dissertação (Mestrado) - Faculdade de Ciências Agronômicas, Universidade Estadual Paulista "Júlio de Mesquita Filho".

DECHEN, A.R. Cálcio no desenvolvimento do tomateiro (Lycopersicum esculentum, Mill.) Piracicaba, 1880.91p. Tese (Doutorado) - Escola Superior de Agricultura "Luiz de Queiroz" - Universidade de São Paulo.

FAYAD, J.A. absorção de nutrientes, crescimento e produção do tomateiro cultivado em condições de campo e de estufa. Viçosa, 1998. 81p. Dissertação (M.S.) - Universidade Federal de Viçosa.

FERNANDES, P.D.; CHURATA-MASCA, M.G.C.; OLIVEIRA, G.D. de; HAAG, H.P. Nutrição de hortaliças: XXVII. Absorção de nutrientes pelo tomateiro (Lycopersicum esculentum Mill.) em cultivo rasteiro. Anais da ESALQ, v.32, p.595 -607, 1975.

FREIRE, F.M; MONNERAT, P.H.; MARTINS FILHO, C.A.S. Nutrição mineral e adubação do tomateiro. Informe
Agropecuário, v.6, p.13-20, 1980.

GARGANTINI, H.; BLANCO, H.G. Marcha de absorção de nutrientes pelo tomateiro. Bragantia, v. 22, p. 693-714, 1963.

HAAG, P.H.; OLIVEIRA, G.D. de; BARBOSA, V.; SILVA NETO, J.M. de. Marcha de absorção dos nutrientes pelo tomateiro (Lycopersicum esculentum Mill.) destinado ao processamento industrial. In: HAAG, H.P.; MINAMI, K. Nutrição mineral de hortaliças. Campinas: Fundação Cargill, 1981. p.447-474.

HERNANDEZ, F.B.T. Potencialidades da fertirrigação. In: VITTI, G.C.; BOARETTO, A.E. Fertilizantes fluidos. Piracicaba: Potafós, 1994. p.215-225.

HO, L.C.; HEWITT, J.D. Fruit development. In: ATHERTON, J.C.; RUDICH, J. The tomato crop. London: Chapman and Hall, 1986. p.201-239.

LYON, C.B.; BEESON, K.C.; ELLIS, G.H. Effects of micronutrients deficiences on growth and vitamin content of the tomato. Botanical Gazette, v.104, p.495-514, 1943.

MAHER, M.J. Growth and nutrient content of a glasshouse tomato crop grown in peat. Scientia Horticulturae, v.4, p.23-26, 1976.

MALAVOLTA, E. Elementos de nutrição mineral de plantas. São Paulo: Ceres, 1980. 251p.

MALAVOLTA, E.; VITTI, G.C.; OLIVEIRA, S.A. Avaliação do estado nutricional das plantas. Piracicaba: Potafos, 1997. 204p.

MARTINS, G. Uso de casa-de-vegetação com cobertura plástica na tomaticultura de verão. Jaboticabal, 1992. 65p. Tese (Doutorado) - Faculdade de Ciências Agrárias e Veterinárias, Universidade Estadual Paulista "Júlio de Mesquita Filho".

MINAMI, K. Nutrição e adubação da cultura do tomate: In: CONGRESSO BRASILEIRO DE OLERICULTURA, 26., Salvador, 1986. Anais. Salvador: EMATER/BA, 1986. p.1-16.

RAIJ, B. van.; CANTARELLA, H.; QUAGGIO, J.A.; FURLANI, A. M.C. Recomendações de adubação e calagem para o Estado de São Paulo. Boletim Técnico. IAC. n.100, p.1-285, 1996. SARRUGE, J.R.; HAAG, P.H. Análises químicas em plantas. Piracicaba: ESALQ, Departamento de Química, 1974. $54 p$. 
STRIPARI, P.C. Vibração e fitorregulador na frutificação do tomateiro (Lycopersicon esculentum Mill.) Híbrido House Momotaro em ambiente protegido. Botucatu, 1999. 60p. Dissertação (Mestrado) - Faculdade de Ciências Agronômicas, Universidade Estadual Paulista "Júlio de Mesquita Filho".

TAKAHASHI, H.W. Nutrição e adubação de tomate estaqueado. In: FERREIRA, M.E.; CASTELLANE, P.D.; CRUZ, M.C.P. Nutrição e adubação de hortaliças. Piracicaba: Potafós, 1993. p.301-322.

TAKAZAKI, P.E.; DELLA VECCHIA, P.T. Problemas nutricionais e fisiológicos no cultivo de hortaliças em ambiente protegido: In: FERREIRA, M.E.; CASTELLANE, P.D.; CRUZ, M.C.P. Nutrição e adubação de hortaliças. Piracicaba: Potafós, 1993. p.481-487.
VILLAS BOAS, R.L.; BOARETTO, A.E.; VITTI, G.C. Aspectos da fertirrigação In: VITTI, G.C.; BOARETTO, A.E. (Coord.). Fertilizantes fluidos. Piracicaba: Potafós, 1994. p.283-308. WARD, G.M. Growth and Nutrient Absorption in Greenhouse Tomato and Cucumber. Proceedings of the American Society of Horticultural Science, v. 90, p.335-341, 1967.

$\overline{\text { Recebido em } 16} .10 .00$ 